\title{
Tubal patency evaluation by saline infusion sonography in cases with unilateral salpingectomy after ectopic pregnancy
}

\begin{abstract}
Introduction: This short report describes a method for tubal patency evaluation by saline infusion sonography (SIS) in cases with unilateral salpingectomy after ectopic pregnancy.

Methods: Five women with previous history of unilateral salpingectomy due to tubal ectopic pregnancy presented with history of secondary infertility were evaluated by SIS. We used an intrauterine insemination (IUI) rigid catheter for instillation of $20 \mathrm{ml}$ normal warm saline into the uterine cavity.

Results: The Douglas pouch of all women was filled with fluid indicating the patency of their tubes. No complications were reported during the procedure or 1 week after. The average time of this procedure was 4 minutes. One of our participants got pregnant 2 months after SIS.
\end{abstract}

Conclusion: SIS could be used to determine the tubal patency in patients with history of unilateral salpingectomy due to ectopic pregnancy.

Keywords: salpingectomy, ectopic pregnancy, tubal patency, saline infusion sonography
Volume 9 Issue 5 - 2018

\author{
Ali H Yosef, Tarek A Farghaly, Mohammed K \\ Ali,Ahmed A Mohamed,Ahmed MAbbas \\ Department of Obstetrics and Gynecology, Faculty of Medicine, \\ Assiut University, Egypt
}

Correspondence: Dr.Ahmed M.Abbas, MD, Department of Obstetrics and Gynecology, Assiut University, Egypt, Women Health Hospital, 7I5II,Assiut Egypt, Tel +20 88 24I4616, Fax +20889202503, Email bmr90@hotmail.com

Received: September 28, 2018| Published: October 08, 2018

\section{Introduction}

Salpingectomy is a common life saving procedure in patients with acute disturbed ectopic. The incidence of ectopic pregnancy in UK was about 11 per 1000 women in 2012. ${ }^{1}$ According to NICE guidelines; the best management of acute disturbed ectopic is salpingectomy. Previous study reported that the cumulative pregnancy rate after unilateral salpingectomy was about $50 \%{ }^{2}$ Although previous study claims that transperitoneal ovum migration from contralateral ovary may be responsible for one third of pregnancies, ${ }^{3}$ however this study was retrospective and two thirds of the patients might conceive from the ipsilateral ovary. This improves the importance of checking the patency of the remaining tube.

Hysterosalpingography (HSG) is considered the best method for screening for tubal disease in infertile patients. ${ }^{4}$ It has some limitations as it is painful with exposure to radiation and need special preparations. Previous trials to utilize saline infusion sonography (SIS) as a screening method to check tubal patency detected only patients with bilateral obstruction..$^{5}$ In our case series, we selected patients with only one tube therefore if saline appears in the peritoneal cavity this can confirm the remaining tube patency.

\section{Materials and methods}

Five women with previous history of unilateral salpingectomy due to tubal ectopic pregnancy were presented to our Infertility Clinic with history of secondary infertility. In all cases, reviewing of their operative records confirmed the presence of aberrantly normal other tube. Regular sexual life and normal semen parameters of the male partner were proved in all cases. Moreover; the included cases were regularly menstruating with evidence of good ovulation. None of included cases had undergone HSG or laparoscopy as an infertility work up.

One week after menstruation; the participants came to our clinics and signed consent for SIS. After that they were subjected to trans-vaginal ultrasound (TVS); uterine volume and cavity as well as absence of Douglas pouch fluid were assessed. All ultrasound evaluations were carried out by an expert level II sonographer using Medison X8 machine (Samsung, Seoul, South Korea).

A speculum then was placed and the cervix swabbed with a cleansing solution. An intrauterine insemination (IUI) rigid catheter was gently inserted and the speculum then removed and replaced by the vaginal ultrasound probe. The instillation of $20 \mathrm{ml}$ normal warm saline into the uterine cavity was done and the uterus was filled with the warmed saline. The Douglas pouch of all women was filled with fluid indicating the patency of their tubes (Figure 1).

The participants were asked to assess the degree of pain provoked by SIS using visual analog score (VAS). No complications were reported during the procedure or 1 week after. The average time of this procedure was 4 minutes. Fortunately; one of our participants got pregnant 2 months after SIS (Table 1). 
Table I Details of women who were subjected to SIS

\begin{tabular}{|c|c|c|c|c|c|c|c|}
\hline No & Age (years) & $\begin{array}{l}\text { Duration of } \\
\text { infertility (years) }\end{array}$ & Parity & $\begin{array}{l}\text { Uterine } \\
\text { volume }\left(\mathrm{cm}^{3}\right)\end{array}$ & Tubal patency & VAS & Outcome \\
\hline I & 30 & 1.5 & 3 & 50 & Yes & 5 & ------ \\
\hline 2 & 32 & 1 & 2 & 45 & Yes & 6 & ------ \\
\hline 3 & 33 & 2 & 1 & 48 & Yes & 5 & ------ \\
\hline 4 & 34 & 2.5 & 0 & 45 & Yes & 4 & ------ \\
\hline 5 & 35 & 1.5 & 0 & 52 & Yes & 5 & Pregnancy occurred \\
\hline
\end{tabular}

SIS, saline infusion sonography;VAS, visual analog scale

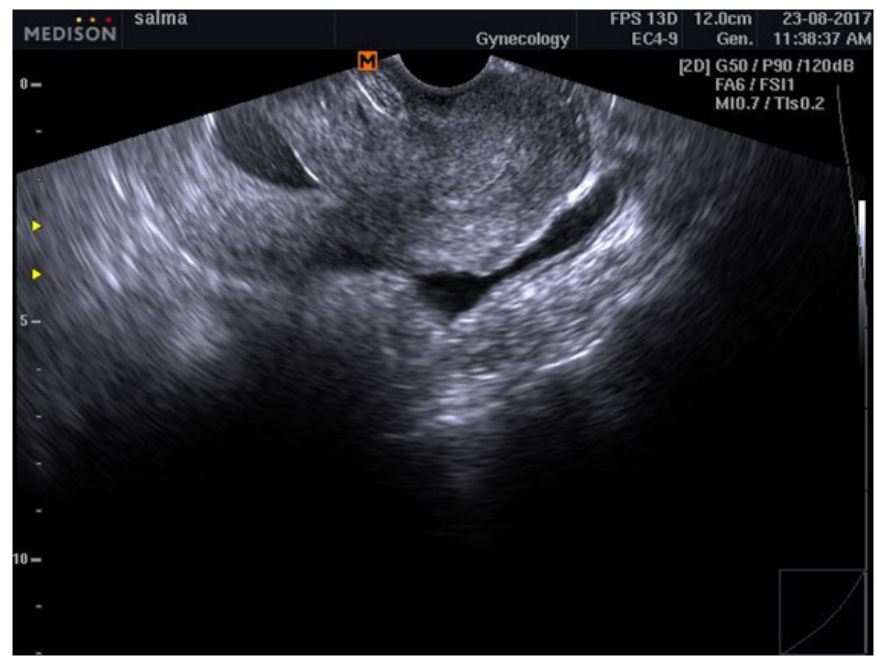

Figure I Transvaginal ultrasound shows uterine cavity and the Douglas pouch filled with the fluid indicating the patency of the tube.

\section{Discussion}

We describe the use of SIS to determine the tubal patency in patients with history of unilateral salpingectomy due to ectopic pregnancy; our technique has some advantages. Firstly, we used the IUI cannula which we found easier in insertion that the Foleys catheter. It is semi rigid so it can found its way easily in the cervical canal without dilatation in nulliparous women.

Previous study used chorionic villous biopsy catheter for the same purpose. ${ }^{6}$ Moreover; its shoulder fits to the cervix and prevents the fluid leakage if the cervical os is wide. Secondly, this technique could be done at the outpatient clinic with no radiation exposure and special preparations. The pain perception by the patients was minimal. Moreover, the use of tubal flushing increases the chance of pregnancy as shown in a Cochrane review.?

Other methods for evaluation of tubal patency include HSG and laparoscopy. HSG will need special preparation, exposure to radiation and radiologist consultation. Laparoscopy will expose the patient to the hazards of surgery and anesthesia. A previous study suggested that SIS has higher sensitivity than HSG in checking tubal patency. ${ }^{8}$ However our main concern on this study that you cannot confirm that both tubes are patent by seeing the fluid in Douglas pouch as it may arise from one tube only.
In our study one tube is removed so we document the patency of the remaining tube. One case got pregnant may suggest the therapeutic effect however the results should be taken with caution due to small number of patients included.

A current study is running in our hospital comparing the accuracy of SIS and HSG in evaluation of tubal patency of such patients with large sample size.

\section{Conclusion}

SIS with the IUI cannula is an easy, simple and promising method that could be used to evaluate the tubal patency in patients with history of unilateral salpingectomy due to ectopic pregnancy.

\section{Acknowledgments}

None.

\section{Conflict of interest}

The author reports no conflict of interest.

\section{References}

1. NICE. Ectopic Pregnancy and Miscarriage: Diagnosis and Initial Management in Early Pregnancy of Ectopic Pregnancy and Miscarriage. Guidance, London: National Institute for Health and Clinical Excellence; 2012 .

2. Ego A, Subtil D, Cosson M, et al. Survival analysis of fertility after ectopic pregnancy. Fertil Steril. 2001;75(3):560-566.

3. Ross JA, Davison AZ, Sana Y, et al. Ovum transmigration after salpingectomy for ectopic pregnancy. Hum Reprod. 2013;28(4):937-941.

4. O Flynn N. Assessment and treatment for people with fertility problems: NICE guideline. British J Gen Pract. 2014;64(618):50-51.

5. Hajishafiha M, Zobairi T, Zanjani VR, et al. Diagnostic value of sonohysterography in the determination of fallopian tube patency as an initial step of routine infertility assessment. J Ultrasound Med. 2009;28(12):1671-1677.

6. Platt LD, Agarwal SK, Greene N. The use of chorionic villus biopsy catheters for saline infusion sonohysterography. Ultrasound Obstet Gynecol. 2000;15(1):83-84.

7. Mohiyiddeen L, Hardiman A, Fitzgerald C, et al. Tubal flushing for subfertility. Cochrane database syst rev. 2015(5):CD003718.

8. Rezk M, Shawky M. The safety and acceptability of saline infusion sonography versus hysterosalpingography for evaluation of tubal patency in infertile women. Middle East Fertility Society J. 2015;20(2):108-113. 